\title{
TIME-RESOLVED 1-10 keV CRYSTAL SPECTROMETER FOR THE Z MACHINE AT SANDIA NATIONAL LABORATORIES *
}

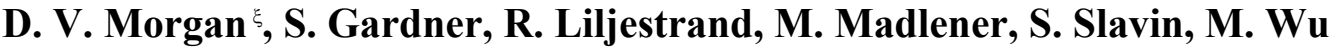 \\ Bechtel Nevada, 182 East Gate Drive, Mail Stop C320 \\ Los Alamos, NM 87544 USA
}

\author{
T. J. Nash \\ Sandia National Laboratories \\ Albuquerque, NM 87185-1196 USA
V. L. Kantsyrev, D. A. Fedin
University of Nevada Reno
Reno, NV 89557 USA

\section{Abstract}

We have designed, fabricated, calibrated, and fielded a fast, time-resolved 1-10 keV crystal spectrometer to observe the evolution of wire pinch spectra at the $Z$ machine at Sandia National Laboratories. The instrument has two convex cylindrical crystals (PET and KAP). Both crystals Bragg reflect $\mathrm{X}$-rays into an array of ten silicon diodes, providing continuous spectral coverage in twenty channels from 1.0 to $10 \mathrm{keV}$. The spectral response of the instrument has been calibrated from 1.0 to $6.3 \mathrm{keV}$ at beamline X8A at the National Synchrotron Light Source. The time response of the $1-\mathrm{mm}^{2}$ silicon detectors was measured with the Pulsed X-ray Source at Bechtel Nevada's Los Alamos Operations, where 2-nanosecond full-width half-maximum (FWHM) waveforms with 700picosecond rise times typically were observed.

The spectrometer has been fielded recently on several experimental runs at the $\mathrm{Z}$ Machine. In this paper, we present the time-resolved spectra resulting from the implosions of double-nested tungsten wire arrays onto 5$\mathrm{mm}$ diameter foam cylinders. We also show the results obtained for a double-nested stainless steel wire array with no target cylinder. The spectrometer was located at the end of a 7.1-meter beamline on line-of sight (LOS) $21 / 22$, at an angle $12^{\circ}$ above the equatorial plane, and was protected from the debris field by a customized dual-slit fast valve. The soft detector channels below $2.0 \mathrm{keV}$ recorded large signals at pinch time coinciding with signals recorded on vacuum $\mathrm{X}$-ray diodes (XRDs). On experiment Z993, the spectrometer channels recorded a second pulse with a hard x-ray emission spectrum several nanoseconds after pinch time.

\section{DESIGN CONSIDERATIONS}

The specifications for the spectrometer, generated by Sandia National Laboratories, included continuous spectral coverage from 1.0 to $10 \mathrm{keV}$, detected by twenty fast channels in continuous x-ray spectral bands. Two convex crystals, a PET crystal with a $2 \mathrm{~d}$ spacing of $8.73 \AA$ and a KAP crystal with a $2 \mathrm{~d}$ spacing of $26.6 \AA$, were cylindrically bent with one-inch bend radii [1] and mounted in the spectrometer to attain the desired spectral response. Channels were designated according to their Bragg angle and associated crystal. The "back-to-back" crystal configuration in the spectrometer allows the instrument to be mounted on a beamline with a clear aperture of less than 2.5 inches. A sketch of the basic components of the spectrometer is shown in Fig. 1.

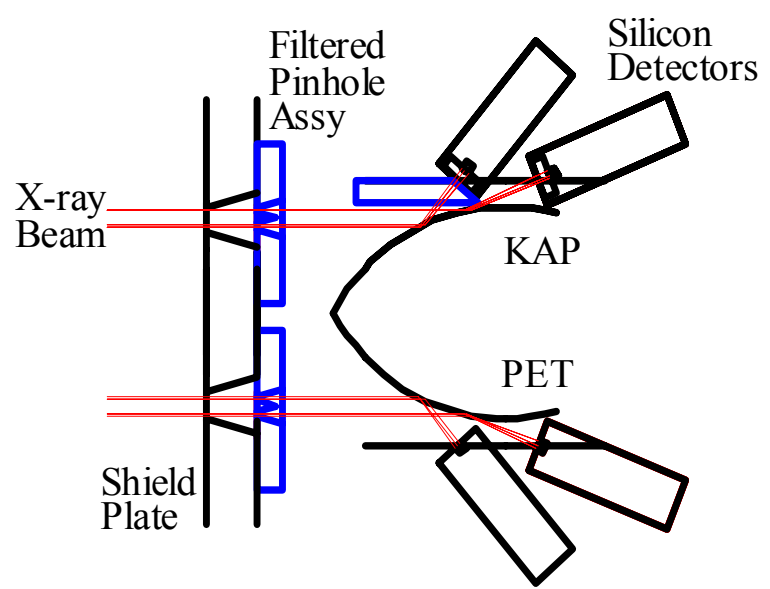

Figure 1. Schematic Diagram of the 1-10 keV Crystal Spectrometer.

\footnotetext{
${ }^{\text {"DOE} / N V / 11718 ~-~ 768 . ~ T h i s ~ w o r k ~ w a s ~ s u p p o r t e d ~ b y ~ t h e ~ U . S . ~ D e p a r t m e n t ~ o f ~ E n e r g y, ~ N a t i o n a l ~ N u c l e a r ~ S e c u r i t y ~ A d m i n i s t r a t i o n ~}$ Nevada Site office, under Contract No. DE-AC08-96NV11718.

छ email: morgandv@nv.doe.gov
} 
The detectors used in the spectrometer were $1.0 \mathrm{~mm}^{2}$ silicon detectors mounted on SMA connectors, which were provided by International Radiation Detectors [2]. The detectors were coupled to the back panel vacuum feedthroughs by vacuum-compatible 50 -ohm flexible cables. This configuration allowed a continuous 50 -ohm transmission line from detection to recording. The active regions of the detectors were arranged in a plane parallel to the beamline axis with a minimum separation of 0.125 inch from the crystal. The axis of each detector was located at twice the Bragg angle with respect to the beamline axis. Placing the active detector area as close to the crystal as possible allows complete coverage of the entire spectral range with the fewest number of channels. A 0.25 -inch- thick copper-tungsten plate was used to shield the detector arrays from the direct beam. Two stainless steel pinhole and filter assemblies are mounted on the copper-tungsten plate with alignment guide pins. The purpose of these pinholes is to allow only x-rays into the spectrometer at the proper location for Braggreflection into the detectors. This reduced background caused by fluorescence and scattering. Background was further reduced by careful selection of the edge filters that cover the pinholes.

The mechanical design for the instrument includes a rugged vacuum chamber with vented, vacuum-compatible hardware; heavy-duty inserts for the vacuum flange and cover bolt holes; and an auxiliary 4.5 -inch pumping port. Standard sized viton seals were used for the cover and the SMA vacuum feedthroughs. Access was provided for removing and replacing the filters without removing the spectrometer from the beamline. All the mechanical components are secured on guide pins, so the instrument can be reassembled to its calibrated mechanical position within 0.001 inch.

\section{SPECTROMETER CALIBRATION}

The fast silicon detectors were tested for their time response at the LAO Pulsed X-ray Source (PXS) prior to installation into the spectrometer. The Pulsed X-ray source delivers a short $(\sim 250 \mathrm{psec})$ electron bunch with a pulse repetition rate of $60 \mathrm{~Hz}$ to a copper anode at $70 \mathrm{keV}$. The silicon detectors were placed in the $\mathrm{x}$-ray beam and connected directly to an electrometer, and the DC current was measured and recorded. Then, a bias tee was placed into the signal path, and a -45 VDC bias was applied to the detector. The signal was recorded on a $3-\mathrm{GHz}$ bandwidth digitizing oscilloscope. A typical detector time response is shown in Fig. 2.

A diagram of the calibration end station is shown in Fig. 3. The end station is designed for $\mathrm{x}$-ray spectral calibrations at beamline X8A at the National Synchrotron Light source. The entire end station is placed on the X8A optical table, which allows for positioning of the spectrometer and end station with five degrees of freedom. The end station has two alignment fluors, which can be lowered into the monochromatic beam at X8A.
The in-beam location of these two fluors was predetermined using an autocollimator, and defined the beam axis and centerline with respect to the spectrometer. The transfer calibration area detector was placed on the upstream side of the end station to measure the total beam power in the monochromatic x-ray beam. This transfer calibration area detector was later calibrated with a reference standard $\mathrm{x}$-ray detector.

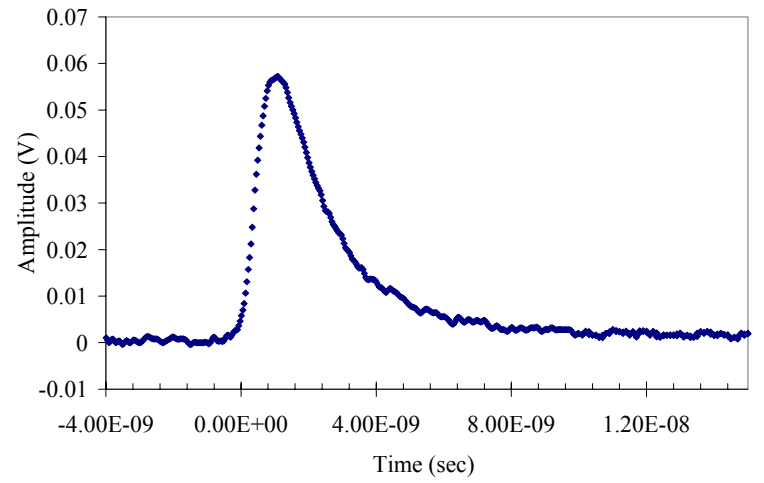

Figure 2. Typical time response of silicon detector with a -45 VDC bias.

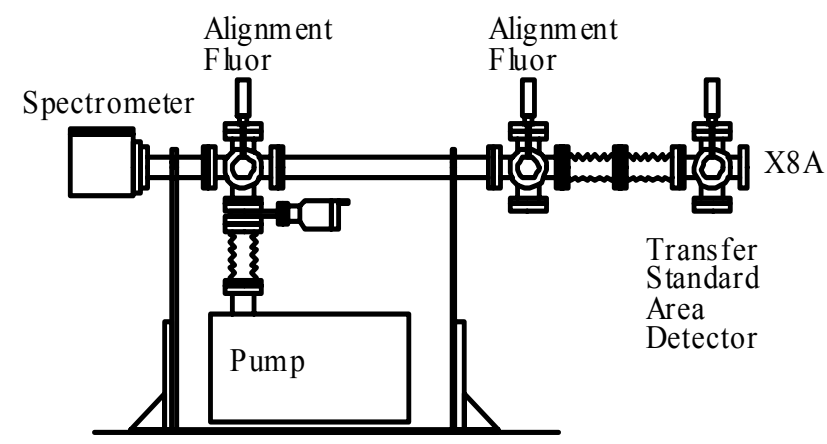

Figure 3. Calibration End Station.

The transfer calibration area detector was placed in the beam and the beam energy was scanned across the entire spectral range to determine the total beam power as a function of x-ray energy. Immediately after the beam power scan, the area detector was removed from the beam, and a spectrometer channel response scan was performed. All measurements were corrected for changes in intensity caused by changes in the ring current. Beam profiles were obtained by first setting the beam energy to midrange within the spectral response profile. The entire assembly was then scanned in the two coordinates orthogonal to the beam with the table positioning stepper motors, and the detector current was recorded into a two-dimensional array. The total beam power, taken together with the beam profile, gives the beam energy flux at the spectrometer in $\mathrm{W} / \mathrm{mm}^{2}$ as a function of the two coordinates orthogonal to the beam. The spectrometer channel response scan was then divided by the beam energy flux to determine the 
calibrated spectral response in units of A-mm²/W. The calibrated spectral response for channel KAP09 is shown in Fig. 4. Four calibrated background channels were placed near the KAP crystal to monitor the fluorescent emission.

Because DC current measurements were performed both at X8A and at the PXS, the impulse response of the spectrometer channels could be determined from the correlation of the DC current at the PXS for the $60-\mathrm{Hz}$ repetition rate with the fast time response (shown in Fig. 2 ). The impulse response is given as

$$
R(t)=f\left[\frac{V(t) R_{D C}}{I_{D C}}\right],
$$

where $R_{D C}$ is the average response across the bandwidth, $V(t)$ is the detector time response to an impulse x-ray source recorded at the PXS, $I_{D C}$ is the average current measurement of the same signal with a source pulse repetition rate $f$. A summary of the calibrated response for the twenty detector channels is shown in Appendix A.

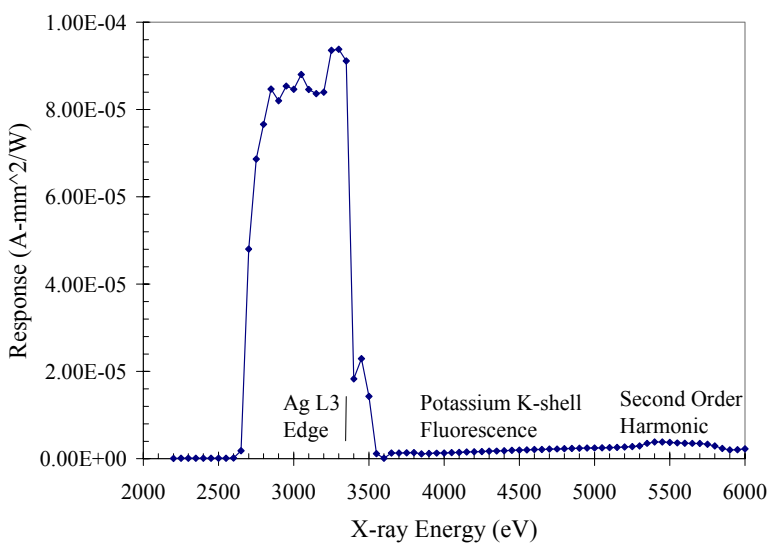

Figure 4. Spectral Response of Channel KAP09. A $1.5-\mu \mathrm{m}$ silver edge filter was used for this channel. Potassium K-shell fluorescence appears for all KAP channels above the potassium K-edge at $3.61 \mathrm{keV}$.

\section{RESULTS FROM Z EXPERIMENTS}

\section{A. Experiment Z974}

Experiment Z974 consisted of a double-nested stainless steel wire array and no target cylinder. The outer nest was $55 \mathrm{~mm}$ in diameter with 104 wires, while the inner nest was $27.5-\mathrm{mm}$ in diameter with 52 wires. This configuration is designed to produce large amounts of 6-8 $\mathrm{keV}$ radiation in a very short $(\sim 4 \mathrm{~ns})$ pulse. The intense radiation caused saturation of the instrument's silicon detectors, which resulted in degradation of their time response. From the time-integrated signals it was possible to make isotropic estimates of the total energy emitted in the three spectral bands recorded for this experiment. These results are shown in Table 1. The chromium He-like emission is evident in channel PET15.

Table 1. Emission spectrum from Z974.

\begin{tabular}{|c|c|c|c|}
\hline Channel & $\begin{array}{c}\text { X-ray Energy } \\
(\mathrm{keV})\end{array}$ & $\begin{array}{c}\text { Bandwidth } \\
(\mathrm{keV})\end{array}$ & $\begin{array}{c}\text { Response } \\
(\mathrm{J} / \mathrm{eV})\end{array}$ \\
\hline PET25 & 3.47 & 0.34 & 9.83 \\
\hline PET17 & 5.08 & 0.74 & 3.05 \\
\hline PET15 & 5.66 & 0.94 & 6.86 \\
\hline
\end{tabular}

\section{B. Experiment Z993}

The load for Experiment Z993 was a double-nested tungsten wire array, with a $5.0-\mathrm{mm}$ diameter foam cylinder as a target. The inner and outer wire array diameters were $20 \mathrm{~mm}$ and $40 \mathrm{~mm}$, respectively. All spectrometer channels recorded two distinct peaks, as shown in Fig. 5. The time delay from the first peak to the second peak was approximately $12 \mathrm{~ns}$. The spectrum of the two peaks is shown in Fig. 6. We observe that the second peak produced a significantly harder $\mathrm{x}$-ray spectrum.

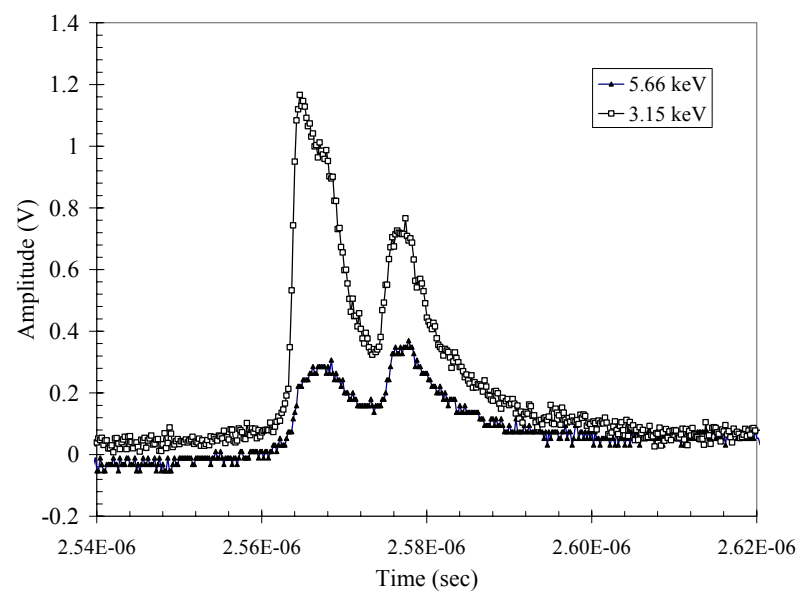

Figure 5. Raw signals recorded from channels PET15 and PET27 for experiment Z993.

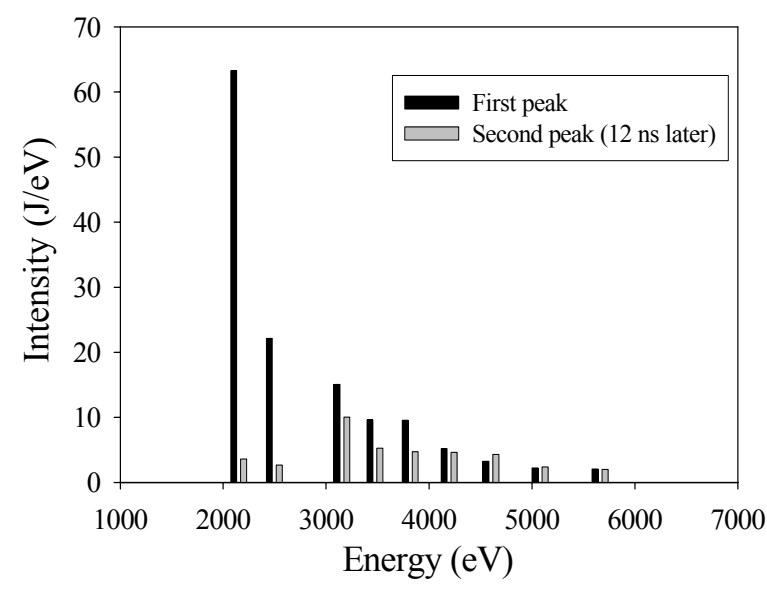

Figure 6. Emission spectrum of the two peaks observed in Fig. 5. for experiment Z993. 


\section{Experiment $Z 1017$}

Experiment Z1017 was virtually identical to Z993 except the diameter of the tungsten wires was reduced slightly from $7.73 \mu \mathrm{m}$ to $7.5 \mu \mathrm{m}$. For this experiment, an array of XRDs was also fielded on LOS $21 / 22$. Unlike Z993, a single X-ray pulse was observed. The peak x-ray emission for the $\mathrm{x}$-ray spectrometer channels below $5 \mathrm{keV}$ coincided with emission from the XRDs on the same lineof-sight. Above $5 \mathrm{keV}$, a delay in the peak emission is observed as shown in Table 2.

Table 2. Time delay of hard x-ray channels.

\begin{tabular}{|c|c|c|}
\hline Channel & $\begin{array}{c}\text { X-ray Energy } \\
(\mathrm{keV})\end{array}$ & $\begin{array}{c}\text { Time delay } \\
\text { from pinch }(\mathrm{ns})\end{array}$ \\
\hline PET15 & 5.66 & 0.7 \\
\hline PET11 & 7.60 & 2.8 \\
\hline KAP31 (Bkgd) & $>3.61$ & 3.3 \\
\hline
\end{tabular}

\section{SUMMARY}

We have demonstrated the performance of the timeresolved 1-10 keV crystal spectrometer on $\mathrm{Z}$ experiments at Sandia National Laboratories. Time-resolved spectral data were recorded in every experiment in which the spectrometer was fielded. We have shown that the transverse emission spectrum in this energy range can have a significant time dependence.

Experiment Z974, with a double-nested wire array of stainless steel, resulted in saturation of the detector channels because of the large x-ray flux. The saturation of the detector channels was eliminated by placing high attenuation filters over the x-ray beam input pinholes on subsequent experiments. This has the undesired consequence of increasing the fraction of background radiation observed in the signal intensity. For $\mathrm{Z}$ experiments with high transverse radiation, such as Z974, it is desirable to field the $1-10 \mathrm{keV}$ crystal spectrometer on a long beamline on LOS $5 / 6$ to reduce the signal intensity by roughly a factor of ten.

For the spectrometer to continue to be fielded on $\mathrm{Z}$ in the future, dedicated digital recording is required. The specifications for the digitizers include a bandwidth greater than $500 \mathrm{MHz}$, and a sampling rate of $2 \mathrm{Gs} / \mathrm{sec}$ or faster. For the experiments described here, fewer than half the available spectrometer channels were recorded. Further investigations are required to mitigate both x-ray background noise and electromagnetic pulses. Development of improved user-friendly software for quick analysis would also be beneficial.

\section{REFERENCES}

[1] X-ray Optics / AAT, 1816 St. Johns Bluff Road 3305, Jacksonville, FL 32246.

[2] International Radiation Detectors, Inc., 2527 W. $237^{\text {th }}$ Street, Unit C, Torrance, CA 90505-5243.

\section{APPENDIX A: SPECTRAL CALIBRATION}

\begin{tabular}{|c|c|c|c|}
\hline Channel & $\begin{array}{c}\text { Mean Energy } \\
(\mathrm{eV})\end{array}$ & $\begin{array}{c}\text { Peak } \\
\text { Bandwidth } \\
(\mathrm{eV})\end{array}$ & $\begin{array}{c}\text { Impulse } \\
\text { Response } \\
(\mathrm{V}-\mathrm{mm} / \mu \mathrm{J})\end{array}$ \\
\hline KAP27 & 1004 & 70 & 0.145 \\
\hline KAP25 & 1077 & 90 & 0.180 \\
\hline KAP23 & 1194 & 130 & 0.731 \\
\hline KAP21 & 1316 & 140 & 0.365 \\
\hline KAP19 & 1445 & 190 & 0.837 \\
\hline KAP17 & 1622 & 260 & 0.682 \\
\hline KAP15 & 1829 & 240 & 0.277 \\
\hline KAP13 & 2150 & 300 & 0.534 \\
\hline KAP11 & 2497 & 440 & 0.623 \\
\hline KAP09 & 3044 & 640 & 1.125 \\
\hline PET27 & 3153 & 240 & 8.486 \\
\hline PET25 & 3474 & 340 & 10.70 \\
\hline PET23 & 3817 & 400 & 10.80 \\
\hline PET21 & 4195 & 480 & 14.83 \\
\hline PET19 & 4601 & 600 & 13.99 \\
\hline PET17 & 5079 & 740 & 10.44 \\
\hline PET15 & 5662 & 940 & 10.74 \\
\hline PET13 & 6400 & 1200 & \\
\hline PET11 & 7600 & 1600 & \\
\hline PET09 & 9300 & 2200 & \\
\hline
\end{tabular}

Copyright Statement. By acceptance of this article, the publisher and/or recipient acknowledges the U.S. Government's right to retain a nonexclusive, royalty-free license in and to any copyright covering this paper.

Disclaimer. This report was prepared as an account of work sponsored by an agency of the U.S. Government. Neither the U.S. Government no any agency thereof, not any of their employees, nor any of their contractors, subcontractors or their employees, makes any warranty or representation, express or implied, or assumes any legal liability or responsibility for the accuracy, completeness, or usefulness of any information, apparatus, product, or process disclosed, or represents that its use would not infringe privately own rights. Reference herein to any specific commercial product, process, or service by trade name, trademark, manufacturer, or otherwise, does not necessarily constitute or imply its endorsement, recommendation, or favoring by the U. S. Government or any agency thereof. The views and opinions of authors expressed herein do not necessarily state or reflect those of the U. S. Government or any agency thereof. 
DISTRIBUTION LIST

U.S. Department of Energy

1 copy

National Nuclear Security Administration

Nevada Site Office

Technical Library

P.O. Box 98518

Las Vegas, NV 89193-8518

U.S. Department of Energy

1 copy

National Nuclear Security Administration

Nevada Site Office

Public Reading Facility

P.O. Box 98518

Las Vegas, NV 89193-8518

U.S. Department of Energy

1 electronic copy

Office of Scientific and Technical Information

P.O. Box 62

Oak Ridge, TN 37831-0062 